\title{
Analisis Quality of Service pemanfaatan Ethernet Over IP(EoIP) Tunnel di MikrotikRouterOS dengan Routing Protocol OSPF
}

\author{
Bongga Arifwidodo \\ Fakultas Teknik Telekomunikasi dan Elektro, Institut Teknologi Telkom Purwokerto \\ Jl. D.I Panjaitan No. 128 Purwokerto \\ bongga@ittelkom-pwt.ac.id
}

Accepted on September 28, 2018

\begin{abstract}
At present the need for integrated data communication has become a major need for an office, especially at this time it tends to have many branch offices to support its business processes. Problems will arise if the head office has a branch office in a different city. Such as more costs in building network infrastructure to connect between headquarters and branches. One solution is to use Ethernet Over IP (EoIP) Tunnel. That is one of the tunneling features of the Mikrotik that provides an efficient solution to this problem. Network tunnel that is built between Mikrotik devices over TCP / IP. In running EoIP tunnel simulation using IPv4 to communicate with each other. Ethernet Over IP (EoIP) is a proprietary protocol, which is only owned by MikrotikOS. The routing protocol used in the EoIP tunnel is OSPF. Open Shortest Path First (OSPF) is one dynamic routing protocol (Dynamic Routing) that is able to maintain, manage and distribute routing information between networks following any dynamic network changes. Then the quality of service is observed with throughput and packet loss parameters. The results of throughput parameters, the performance of video streaming services reaches $280.45 \mathrm{kbits} / \mathrm{Sec}$. In the video streaming communication service, the average OSPF EoIP Tunnel packet loss reaches $0.92 \%$.
\end{abstract}

Keywords: EoIP, OSPF, Mikrotik, IPv4

\section{INTRODUCTION}

$\mathbf{S}_{\mathrm{b}}^{\mathrm{a}}$ aat ini perkembangan teknologi informasi dan komunikasi bergerak begitu cepat dan dinamis. Dimana berdampak pada penggunaan layanan internet pun semakin tinggi. Menurut data Asosiasi penyelenggaraan Jasa Internet Indonesia - APJII menunjukkan statistik 132,7 juta jiwa pada tahun 2016 sekitar 51,8\% dari total warga Indonesia 256,2 juta[1]. Keberadaan internet pada aspek penggunaan layanan internet dapat di pandang sebagai media bantu (support) seperti halnya jasa pos atau kurir, dapat dialihkan dengan menggunakan e-mail, di sisi lain, ada yang menjadi tulang punggung (backbone) dalam proses bisnis sebuah organisasi. Kebutuhan akan akses internet dewasa ini sangat tinggi sekali. Baik untuk mencari informasi, artikel, pengetahuan terbaru atau bahkan hanya untuk chating[2]. Penggunaan koneksi internet bersama-sama, baik dalam sekala kecil hingga sekala besar memerlukan adanya gateway dan router yang dapat dihandalkan. 
Pada pembangunan suatu infrastruktur jaringan, tentu membutuhkan beberapa media perangkat, baik perangkat keras (hardware) maupun perangkat lunak (software). Salah satu media dari perangkat keras yaitu router, yaitu sebuah device atau alat yang berfungsi untuk meneruskan paket-paket data dari sebuah jaringan ke jaringan lain yang berbeda. Dengan demikian host-host dari setiap jaringan dapat berkomunikasi dengan host-host dari jaringan lainnya. Router dapat berupa alat yang dirancang khusus sebagai router (decated router) atau bisa menggunakan Pesonal Computer (PC) yang difungsikan sebagai router dengan penambahan instalasi system operasi router. Sebuah PC dapat berfungsi sebagai router jika PC tersebut memiliki sistem operasi yang berkemampuan seperti halnya router, misalnya Mikrotik RouterOS ${ }^{\mathrm{TM}}$. Di dalam router terdapat sebuah protokol yang mengatur komunikasi antar router, yaitu routing protokol. Selain itu routing prokotol mengijinkan router-router untuk berbagi informasi tentang jaringan dan koneksi antar router [3].

Saat ini kebutuhan akan komunikasi data yang terintegrasi sudah menjadi kebutuhan yang utama bagi sebuah kantor, terlebih saat ini cenderung memiliki banyak kantor cabang sebagai penunjang proses bisnisnya. Seperti melakukan file sharing, komunikasi Voice over Internet Protocol, dan pertukaran data dalam jaringan lainnya. Masalah akan timbul apabila kantor pusat, memiliki beberapa kantor cabang yang berada di kota yang berbeda. Salah satunya menyebabkan biaya lebih dalam hal membangun infrastruktur jaringan untuk menghubungkan antara kantor pusat dan cabang. Di samping itu dibutuhkan juga koneksi yang dengan kemanan yang handal. Dalam hal keamanan Virtual Privat Network (VPN) digunakan untuk membuat terowongan (tunnel) dari ujung ke ujung konekstivitas melalui jaringan pihak ketiga seperti intranet atau extranet[4]. Ethernet Over Ip (EoIP) Tunnel merupakan salah satu fitur tunneling pada mikrotik yang memberikan solusi efisien untuk masalah ini.

\section{KAJIAN PUSTAKA}

\section{A. Virtual Private Network}

Virtual Private Network (VPN) adalah tiruan dari sebuah fasilitas Wide Area Network (WAN) privat menggunakan fasilitas IP (termasuk Internet Publik, atau backbone IP Privat). VPN menyediakan komunikasi privat antar end user, seperti remote office dan telecommuters [5]. Banyak organisasi menggunakan VPN untuk menghubungkan kantor, home office, rekan bisnis dan masih banyak lagi. Selain karena murah dan mudah digunakan, VPN juga digunakan karena mengutamakan keamanan. "VPN merupakan sebuah sarana untuk mengamankan dan memprivatkan pengiriman data melalui sebuah infrastruktur jaringan yang tidak aman dan dapat digunakan bersama (shared) [6]. Jaringan VPN bisa disebut aman karena semua data yang ditransmisikan melalui sebuah terowongan (tunnel) selalu dienskripsi menggunakan algoritma-algoritma tertentu, bergantung pada protokol yang digunakan.

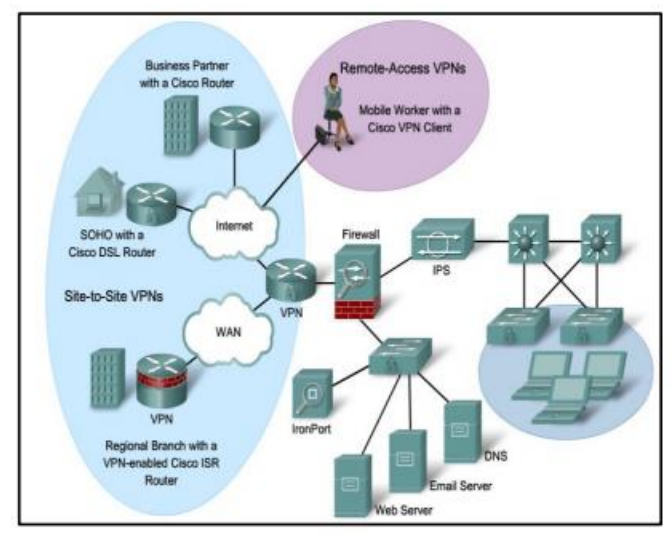

Gambar 1 komponen dan teknologi VPN [6] 


\section{B. VPN tunneling}

Tunneling merupakan dasar atau inti dari teknologi VPN. Tunneling adalah teknik enskapsulasi seluruh paket data ke dalam format protokol lain [7]. Kemudian mengijinkan penggunaan jaringan publik seperti internet untuk membawa data kepada pengguna seolah-olah pengguna memiliki akses ke jaringan privat [6]. Jika ditempatkan pada model OSI layer, tunneling bekerja pada layer 2.

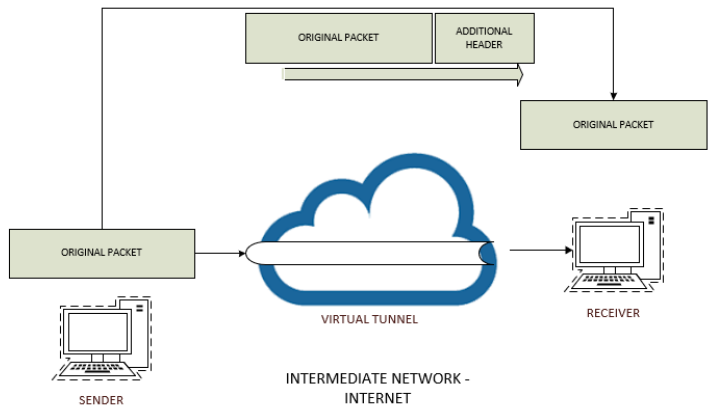

Gambar 2 proses tunneling

Gambar 2 menjelaskan bagaimana proses pengenkapsulasi paket data ke dalam format lain. Paket yang dienskapsulasi tidak dirubah, tetapi hanya ditambahkan sebuah header yang pada saat paket ditransmisikan ke dalam jaringan. Hal ini membuat paket yang asli tidak berubah nilainya baik ketika paket dikirim maupun diterima [5].

\section{Ethernet over Internet Protocol (EoIP)}

Ethernet over Internet protocol merupakan protokol yang dikembangkan oleh MikrotikOS yang membuat sebuah koneksi Ether Tunnel antara dua router dengan menggunakan koneksi TCP/IP. Interface EoIP terlihat sebagai interface etehernet biasa (secara logikal). Ketika fungsi bridging diaktifkan, semua data yang ditransmisikan melalui ethernel protocol pada kedua router akan dijembatani (bridge) seolah-olah kedua router dihubungkan dengan kabel. Urutan enskapsulasi pada protokol EoIP yakni, pertama internet protocol (IP) pada layer 3 akan dienskapsulasi dengan menggunakan teknologi ethernet II pada layer 2. Hasil enskapsulasi tersebut kemudian mengenskapsulasi protokol GRE (Generic Routing Encapsulation). EoIP ini menggunakan protokol generic routing encapsulation - GRE (RFC1701). Dengan cara inilah proses pembentukan EoIP tunnel terjadi dan digunakan untuk mengirim dan mengirim data. Tunnel protokol EoIP bekerja menggunakan tunnel ID yang harus bernilai sama antara kedua router yang memiliki EoIP interface dalam membentuk EoIP tunnel[5].

\section{Open Shorthest Path First (OSPF)}

Merupakan routing protokol berjenis Interion Gateway Routing Protocol (IGRP) dan memiliki sifat routing protokol terbuka dan konfigurasinya bisa di terapkan di router dari vendor manapun. Routing protokol ini menggunakan konsep herarki routing dimana OSPF membagi-bagi jaringan menjadi beberapa tingkatan dan tingkatan-tingkatan ini diwujudkan dengan menggunakan sistem pengelompokan area. Routing Protocol ini akan mengarahkan lalu lintas data didalam jaringan dengan berdasarkan hubungan ukuran antar data yang telah ditentukan oleh seorang Administrator jaringan. Masing - masing Router yang terdapat didalam AS (Autonomous Systems) akan menghitung jalur yang paling pendek dan membuat tabel tujuan yang dipergunakan untuk mengirimkan paket data kepada Router berikutnya dalam rangka untuk mengirimkan paket data menuju tujuannya yang terakhir[8]. Routing protokol OSPF bekerja menggunakan algoritma linkstate atau Djikstra dimana fungsi dari algoritma ini memperbaiki informasi database dari informasi topologi. 


\section{METODE PENELITIAN}

Pada bab ini dibahas mengenai proses perancangan dan implementasi berupa simulasi jaringan. Layanan yang digunakan untuk pengujian adalah layanan video streaming di jaringan simulasi yang menggunakan EoIP Tunnel dengan skenario EoIP Tunnel OSPF. Menggunakan satu server dan satu client. Kemudian pengambilan data yang sedemikian rupa untuk melihat performa kualitas layanan pada jaringan.

A. Simulasi penelitian

Proses pengujian simulasi jaringan dilakukan dengan menggunakan empat unit perangkat yang berupa dua unit PC, satu PC sebagai server video streaming dan satu PC untuk menjalankan aplikasi simulator serta dua unit laptop sebagai client. Implementasi perangkat dijelaskan pada Gambar 3.

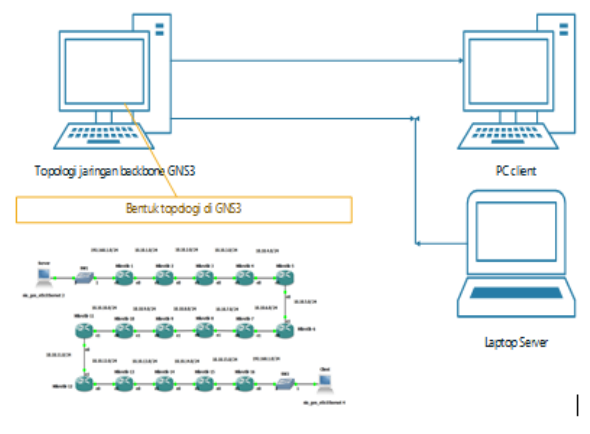

Gambar 3 simulasi konfigurasi jaringan

Pada Gambar 3 di atas memperlihatkan simulasi implementasi keseluruhan perangkat yang digunakan, dimana dibagi menjadi tiga komponen utama yaitu aplikasi simulasi jaringan, server video streaming dan client. Pengoprasian aplikasi simulasi jaringan dijalankan oleh PC yang berfungsi sebagai backbone pengalamatan router pada aplikasi simulasi menggunakan IPv4, laptop server berfungsi sebagai server yang menyediakan layanan video streaming dengan memanfaatkan fitur pada aplikasi video lan client VLC media player, dan pada sisi client juga menjalankan aplikasi VLC media player untuk menerima video streaming yang didapat dari server lalu pada sisi client untuk meng-capture trafik data layana streaming video. Aplikasi wireshark sebagai tool network digunakan untuk meng-capture trafik sebagai hasilnya akan dianalisa untuk mendapatkan nilai QoS-nya. Laptop server dan pc client akan dihubungkan ke PC backbone yang menjalankan aplikasi simulasi jaringan dengan menggunakan kabel koneksi yaitu kabel Unshield Twisted Pair (UTP).

\section{B. Topologi}

Proses pengujian simulasi jaringan menggunakan tiga buah perangkat yakni dua perangkat PC dan satu perangkat laptop. Dimana satu PC berfungsi sebagai core backbone, dimana PC yang menjadi core backbone menjalankan aplikasi simulasi jaringan dan PC satunya sebagai PC client yang bertugas untuk menganalisa trafik data yang diterima dari PC server menggunakan aplikasi wireshark dan VLC sebagai media yang digunakan untuk menerima trafik data. Kemudian satu laptop yang berfungsi sebagai server dimana fungsinya melakukan media streaming dengan aplikasi yang jalankan hanya VLC media player. 


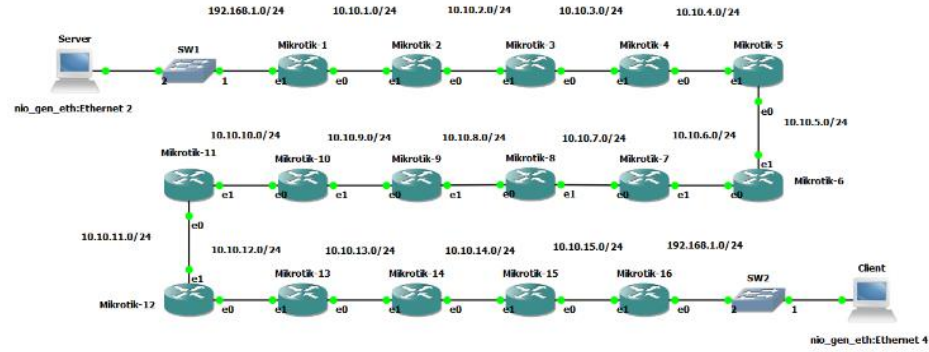

Gambar 4 konfigurasi EoIP tunnel OSPF

Penelitian ini dilakukan untuk menguji layanan video streaming menggunakan aplikasi VLC media player dengan pengalamatan IP yang digunakan adalah IPv4. Pengujian dilakukan untuk mengetahui berapa nilai Quality of Service (QOS) pada layanan EoIP tunnel OSPF. Pada Gambar 4 merupakan perancangan topologi EoIP Tunnel OSPF, dimana langkah pertama yang akan dilakukan adalah pembuatan routing OSPF pada router mikrotik. Router yang digunakan sebanyak 16 router dimana port yang digunakan hanya dua port. Yaitu port E0 dan port E1. Pada router mikrotik 1 pada port E0 yang mengarah ke router mikrotik2 diberikan alamat IP 10.10.1.1 dan pada port E1 diberikan alamat 192.168.1.100.

Routing OSPF hanya dilakukan pada port yang mengarah ke router mikrotik 2,3,4, sampai 16, kemudian pada router 16 routing OSPF hanya diterapkan pada port E1 dan port E0 tidak diterapkan OSPF. Setelah routing OSPF sudah diterapkan selanjutnya pembuatan tunneling, ada hal yang menarik untuk pembuatan tunnel konfigurasi menggunakan aplikasi Winbox. Dan konfigurasinya pun tidak dilakukan di aplikasi simulasi jaringan melainkan melalui aplikasi dari Winbox yang ada pada PC client dan Laptop server. dan selanjutnya dilanjutkan dengan konfigurasi EoIP Tunnel RIPv2 dan konfigurasi topologi tidak jauh berbeda dengan EOIP Tunnel OSPF.

\section{Konfigurasi OSPF}

Pada penelitian ini skenario pertama yang dibuat adalah skenario EoIP Tunnel OSPF. Sebelumnya konfigurasi OSPF dikonfigurasikan terlebih dahulu. Konfigurasi ini menggunakan 16 router dengan tujuan untuk menghitung distance vector dari EoIP Tunnel OSPF. Pengalamatan perangkat menggunakan IPv4 contoh konfigurasi yang akan ditampilkan hanya 1 dari 16 router:

[MikroTik] > ip address add address $=10.10 .1 .2 / 24$ interface $=$ ether 2

[MikroTik] > ip address add address=10.10.2.1/24 interface $=$ ether 1

Setelah pengalamatan IPv4 pada perangkat router mikrotik2, dilanjutkan dengan konfigurasi OSPF:

[MikroTik] > routing ospf network add network 10.10.1.0/24 area $=$ backbone

[MikroTik] > routing ospf network add network 10.10.2.0/24 area $=$ backbone

Konfigurasi diatas merupakan konfigurasi dari router mikrotik2, konfigurasi OSPF diterapakan pada 16 router yang digunakan penelitian ini setelah konfigurasi OSPF dikonfigurasikan kemudian dilanjutkan dengan konfigurasi EoIP Tunnel.

\section{Konfigurasi EoIP tunnel}

EoIP Tunnel dapat dikonfigurasikan melalui penggunaan aplikasi winbox dimana untuk melakukan administrasi terhadap MikrotikOs. Konfigurasi ini tidak dilakukan dari aplikasi simulasi jaringan melainkan dari PC dan laptop yang berfungsi sebagai server dan client. 


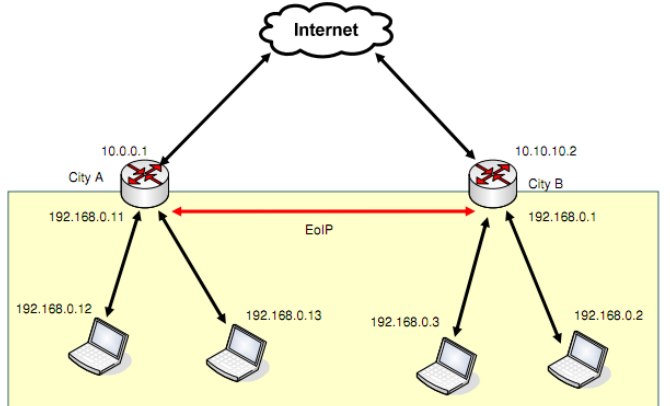

Gambar 4 Contoh konfigurasi EoIP tunnel [10]

Penambahan interface eoip :

[MikroTik] interface eoip > add

[MikroTik_1] interface eoip > add name to_mt2 tunnel-id 1 remote-address x.x.x.x

[MikroTik_1] interface eoip> enable 0

\section{E. Parameter Quality of Service}

\section{- THROUGHPUT}

Throughput merupakan salah satu parameter dalam Quality of Service dimana fungsinya untuk melihat perbandingan jumlah data yang di proses kirim dalam waktu pengamatan tertentu dengan satuan bits per second (bps). Hasil dari throughput ini jika nilainya semakin besar maka hasilnya semakin bagus. Persamaan 1 merupakan rumus dalam penghitungan throughput [10].

$$
\text { troughput }=\frac{\text { (jumiah bit datayang diterima benar) }}{\text { Wahtu pengiviman bit }} \text { bps }
$$

persamaan 1 persamaan throughput

\section{- $\quad$ PACKET LOSS}

Packet loss merupakan salah satu parameter dalam Quality of Service dimana fungsinya untuk melihat jumlah packet data yang mengalami ketidak sempurnaan (kecacatan) atau tidak tertuju sampai alamat penerima secara utuh dalam waktu pengamatan tertentu. Perhitungan rumus untuk packet loss dapat dilihat pada persamaan 2 .

$$
\text { packet loss }=\frac{(\text { Packets transmitted-Packets received })}{\text { Packet transmitted }} \times 100 \%
$$

Sebuah parameter dikatakan baik bilamana memenuhi standard nilai yang sudah disepakati dan pada Tabel 1 merupakan standar nilai dari packet loss[11].

Tabel 1 Standar Packet loss

\begin{tabular}{|c|c|}
\hline KATEGORI & PACKET LOSS RATIO (PLR) \\
\hline Baik & $0-0,5 \%$ \\
\hline Cukup & $0,5 \%-1,5 \%$ \\
\hline Kurang baik & $>1,5 \%$ \\
\hline
\end{tabular}

\section{HASIL DAN ANALISA}

Berdasarkan pengamatan saat simulasi pengujian yang dilakukan, dapat kita peroleh hasil data pengukuran dan analisa mengenai Quality of Service. 


\section{- $\quad$ THROUGHPUT}

Throughput merupakan salah satu parameter dalam Quality of Service yang menyajikan rasio kecepatan (rate) transfer data aktual yang diukur dalam satuan bit per second (bps). Throughput pada networking diartikan sebagai tingkat pengiriman pesan berhasil melalui saluran komunikasi yang di amati dari sisi destination. Dengan 30 sampling yang dilakukan pada layanan komunikasi video streaming yang dilakukan memperoleh hasil rata-rata throughput EoIP Tunnel OSPF mencapai $280.45 \mathrm{kbits} / \mathrm{sec}$. Pada topologi yang menggunakan routing protokol OSPF memiliki metrik, yaitu cost dimana memiliki fungsi untuk menghitung dan menentukan rute terbaik. Protokol OSPF akan melakukan inisiasi rute atau jalur yang terdapat didalam jaringan komputer dengan mengirimkan Hello Packet yang berguna untuk memetakan rute atau jalur jaringan computer. Karena pada pengiriman data dengan protokol routing OSPF sangat dipengaruhi oleh cost dari setiap path yang digunakan. Semakin tinggi cost akan semakin cepat paket dihantarkan, berbanding lurus semakin besar nilai throughput maka semakin cepat paket sampai pada tujuan.

\section{- PACKETLOSS}

Packet loss adalah parameter yang menggambarkan suatu kondisi yang menunjukann jumlah total paket yang hilang, dikarenakan tabrakan antar data (collision) dan kelebihan kapasitas (congestion). Pada jaringan internet hal ini berpengaruh pada semua aplikasi karena retransmisi akan mengurangi efisiensi jaringan secara keselurahan meskipun jumlah bandwidth cukup tersedia untuk aplikasi tersebut. Artinya semakin kecil nilai packet loss maka semakin baik kinerja dari jaringan karena tidak ada paket yang hilang pada saat proses pengiriman data. Dengan 30 sampling pada layanan komunikasi video streaming yang dilakukan memperoleh hasil rata-rata packet loss EoIP Tunnel OSPF mencapai 0.92\%. Hal ini dikarenakan pada router OSPF mempunyai sebuah mekanisme untuk menentukan router tetangganya dan dapat melakukan hubungan, mekanisme ini disebuat dengan "Hello protocol" dengan cara mengirimkan paket berukuran kecil secara periodik ke dalam jaringan atau sebuah perangkat yang terhubung langsung dengannya.

\section{Kesimpulan}

Berdasarkan hasil data penelitian dan analisa Quality of Service pada layanan EoIP tunnel dengan protokol routing OSPF dapat ditarik kesimpulan. Hasil parameter throughput,performansi layanan video streaming mencapai $280.45 \mathrm{kbits} / \mathrm{sec}$. Pada layanan komunikasi video streaming yang dilakukan memperoleh hasil rata-rata packet loss EoIP Tunnel OSPF mencapai $0.92 \%$. Protokol RTP memberikan kualitas streaming yang lebih baik ketimbang UDP karena RTP merupakan penyempurnaan dari TCP dan UDP. Dimana protokol RTP hasil QoS yang dapat dianalisa hanya throughput dan packetloss sedangkan QoS jitter dan delay hanya dapat dibaca pada protokol RTCP. 


\section{REFERENSI}

[1] Widiartanto, Yoga Hastyadi, "Pengguna Internet Indonesia Capai 132juta.(Online)", 2016.

[2] Puspitasari, Nila, "Implementasi Mikrotik Sebagai Solusi Router Murah Dan Mudah", Seminar Nasional Teknologi, Snt, 2007.

[3] Nurhayati, Ade, "Simulasi Perbandingan Protokol Routing Ospf Dan Isis Menggunakan Gns3", Jurnal Ict Penlitian Dan Penerapan Teknologi, 2013.

[4] Hayale, Ws, "Implementing Virtual Privat Network Using Ipsec Framework", International Journal Of Engineering Research \& Technology, 2014

[5] Susanto, Rt, "Analisis Perbandingan Performa Point-To-Point Tunneling Protocol Dan Ethernet Over Internet Protocol Dalam Membentuk Vpn", Informatika Vol 9, No. 1, 2013.

[6] Vachon, B, "Accessing The Wan-Ccna Exploration Companion Guide", Cisco Press, 2008.

[7] Gupta, M, "Building A Virtual Private Network", Cisco Press, 2006.

[8] Utomo, P, "Pengembangan Jaringan Komputer Universitas Surakarta Berdasarkan Perbandingan Rip Dan Ospf, Ijns Vol 1, 2012.

[9] Riyadi, Valens, "Modul Certified Mikrotik Traning Basic Class", Citraweb, 2010.

[10] B. A, Forouzan, "Data Communication And Networking 5e", Mcgraw Hill International Edition, 2013.

[11] Tiphon, "Telecommunication And Internet Protocol Harmonization Over Network (Thipon) General Aspec Of Quality Of Service (Qos)", Dtr/Tiphon-05006, Vol. 2, 1999. 